\title{
Do adaptative changes occur in the achilles tendons of endurance runners?
}

\author{
Serra Pol M. ${ }^{1}$ Pons Hernández A. ${ }^{2}$ Barea Vega E. ${ }^{3}$ Gómez Luque M. ${ }^{4}$ \\ 1 Physiotherapist at Fisioplanet. Col n 726 Illes Balears, Spain \\ ${ }^{2}$ Physiotherapist at Fisioplanet. Col n ${ }^{\circ} 943$ Illes Balears, Spain \\ 3 Physiotherapist at Fisioplanet. Col n 494 Illes Balears, Spain \\ ${ }^{4}$ Physiotherapist at Fisioplanet. Col n 1135 Illles Balears, Spain \\ Rev Fisioter Invasiva 2019;2:83.
}

\begin{abstract}
Introduction and Aim Several studies associate tendinopathies with structural changes in the Achilles tendon (AT). However, few studies have demonstrated whether long distance running training can generate structural changes at the level of the AT. The aim of this study was to determine whether adaptive changes exist, both structural and functional, in the AT of asymptomatic endurance runners with no history of lesions to the AT.

Material and Methods A cross-sectional descriptive study. In total, 14 subjects were selected and divided into two groups of 7 subjects each. The intervention group (IG) comprised all usual runners, running over $60 \mathrm{~km}$ per week, with no previous lesion to the AT. The control group (CG) included all active subjects but who did not perform competitive sports nor did they run more than $10 \mathrm{~km}$ per week. The ankle dorsal flexion (ADF) of each subject was measured together with the index of reactive force (IRF), and the width of the AT body was measured using ultrasound, together with the level of hypervascularization, the presence of hypoechoic areas and the presence of hyperechoic areas. To measure ADF, the validated measurement was used with the application (App) Dorsiflex for IPhone. To calculate IRF, the validated measure of the Drop Jump, test from the App My Jump 2 was used. The ultrasound assessment was always performed by the same examiner. The ultrasound machine was a General Electric, Logiq V2 model for measuring both feet: the width of the AT body, the degree of hyper vascularization, the presence of hypoechoic areas and the presence of calcifications. The subject was placed in prone, with the foot hanging off the table and the ankle was in $90^{\circ}$ flexion. The examiner was placed on the same side as the lower limb examined.

Results The means of the results obtained and p-values of significance were as follows: $A D F=46^{\circ} \mathrm{CG} 43.6^{\circ} \mathrm{IG}(\mathrm{p}>0.005)$. IRF $=0.92$ CG $1.07 \mathrm{IG}(\mathrm{p}>0.005)$ Ultra-

\section{Keywords}

- achilles tendon

- ultrasonography

- physiological adaptation

- running sound $=$ CG $43 \%$ presence of vascularization outside the tendon; IG $83 \%$ presence of vascularization outside the tendon.

Conclusions No significant evidence exists to support that the AT in endurance runners without a history of injuries, presents functional adaptations. However, it seems that in endurance runners, there is a greater presence of vessels in Kager's fat pad, although it is necessary to obtain data from a larger population to confirm and establish the possible relationships of these changes.
\end{abstract}

DOI https://doi.org/ 10.1055/s-0039-3401865. ISSN 2386-4591.
Copyright $\odot 2019$ by Thieme Revinter Publicações Ltda, Rio de Janeiro, Brazil 